\title{
Program Sanitarian Cilik di SD Negeri 011 Samarinda sebagai Sarana Edukasi Pola Perilaku Hidup Bersih dan Sehat pada Masyarakat
}

\author{
Andi Daramusseng1, Tri Budi Julianti² \\ ${ }_{1}$ Universitas Muhammadiyah Kalimantan Timur
}

\begin{tabular}{l} 
Article History \\
\hline Received 03.04.2019 \\
Received in revised form \\
20.06.2019 \\
Accepted 26.07 .2019 \\
Available online 20.08 .2019
\end{tabular}

\begin{abstract}
PROGRAM OF THE LITTLE SANITARIAN IN SAMARINDA ELEMENTARY SCHOOL 011 AS AN EDUCATION FACILITY FOR CLEAN AND HEALTHY LIFESTYLE PATTERNS FOR THE COMMUNITY. Health is a human right and an investment for a productive life. Therefore healthy conditions must always be sought. One effort that can be done by the community is to clean and healthy living behavior. Based on the Health Profile of East Kalimantan, 2015 obtained data of PHBS Household Coverage in Samarinda City by $43 \%$. This shows there is still a lack of understanding of the community about PHBS, especially people living around the Karang Mumus River. Based on this, one urgent program is carried out to improve public understanding of PHBS as a program little sanitarian. This program involves elementary school-age children because at that age; it is a golden age to instill clean and healthy living behavior values so that it has the potential as a change agent to promote PHBS. This program was implemented in Elementary School 011 Samarinda through the provision of clean and healthy living behavior materials and practices to 90 students in class 3 and 4. The selection of Little sanitarian cadres was made through the selection of real understanding that had been given. The results of this activity were selected six cadres of little sanitarian, namely 1 class 3 and 5 class 4 . This activity is expected to continue with the guidance of Little Sanitarian cadres and cooperation with related parties to hold the movement of Little Sanitarian.
\end{abstract}

KEYWORDS: Little Sanitarian, Clean and Healthy Behavior.

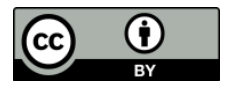

This is an open access article distributed under the terms of the Creative Commons Attribution 4.0 International License, which permits unrestricted use, distribution, and reproduction in any medium, provided the original work is properly cited. ○ 2019 Andi Daramusseng, Tri Budi Julianti.

\section{PENDAHULUAN}

Kesehatan adalah hak asasi manusia dan sekaligus investasi untuk kehidupan yang produktif. Dalam undang-undang no. 23 tahun 1992, disebutkan bahwa kesehatan adalah keadaan sejahtera dari badan, jiwa dan sosial yang memungkinkan setiap orang hidup

${ }^{1}$ Corresponding author: Program Studi Kesehatan Lingkungan, FKF Universitas Muhammadiyah Kalimantan Timur; Jl. Ir.H.Juanda No. 15, Samarinda, Kaltim, Indonesia; Email: andidaramusseng@umkt.ac.id 
produktif secara sosial dan ekonomis. Oleh karena itu, perlu adanya upaya pembangunan dibidang kesehatan untuk tercapainya kesadaran, kemauan dan kemampuan untuk hidup sehat bagi seluruh masyarakat. Dalam upaya mencapai tujuan tersebut, perlu integrasi dari seluruh komponen baik pemerintah, tenaga kesehatan maupun masyarakat. Pemerintah dipandang perlu untuk mengadakan program-program yang berkaitan dengan upaya kesehatan, sedangkan tenaga kesehatan menjadi pembimbing pelaksanaan program tersebut dan masyarakat juga harus berperan aktif dalam mengupayakan kesehatannya sendiri. Salah satu upaya yang dapat dilakukan masyarakat adalah dengan berperilaku hidup bersih dan sehat (PHBS). Untuk itu masyarakat perlu dibekali pengetahuan dasar tentang perilaku hidup bersih dan sehat.

Berdasarkan Profil Kesehatan Provinsi Kalimantan Timur Tahun 2015 diperoleh data Cakupan Rumah Tangga Ber-PHBS Di Kota Samarinda sebesar 43\%. Hal ini menunjukkan masih kurangnya pemahaman masyarakat tentang perilaku hidup bersih dan sehat. Oleh karena itu, perlu adanya suatu program untuk meningkatkan pemahaman masyarakat mengenai perilaku hidup bersih dan sehat (PHBS). Sesuai dengan Kepmenkes nomor 373 Tahun 2007 tentang Standar Profesi Sanitarian bahwa sanitarian harus berperan secara aktif, terarah dan terpadu dalam pembangunan kesehatan nasional. Berdasarkan hal tersebut, salah satu program yang dapat dilakukan untuk meningkatkan pemahaman masyarakat mengenai perilaku hidup bersih dan sehat (PHBS) adalah melalui program sanitarian cilik. Program sanitarian cilik melibatkan anak usia sekolah karena usia sekolah merupakan masa keemasan untuk menanamkan nilai-nilai perilaku hidup bersih dan sehat (PHBS) sehingga berpotensi sebagai agen perubahan untuk mempromosikan PHBS baik di lingkungan sekolah, keluarga maupun masyarakat.

Sasaran program Sanitarian cilik ini adalah siswa sekolah dasar kelas 3 dan 4 yang berusia sekitar 8-11 tahun. Program Sanitarian Cilik diharapkan dapat efektif untuk meningkatkan pemahaman masyarakat mengenai perilaku hidup bersih dan sehat (PHBS). Sanitarian cilik ini nantinya akan membawa bekal ilmu yang didapat dalam kehidupan sehari-hari dan mampu mensosialisasikan pengetahuan yang diperolehnya mulai dari lingkup keluarga, sekolah hingga masyarakat luas. Pada usia ini, anak telah memiliki kemampuan "operational thinking" yaitu mampu memahami penyebab kausal dan pemahaman kuantitatif. Oleh karena itu, metode pembelajaran yang tepat pada siswa usia ini adalah dengan memberikan kesempatan kepada mereka untuk melihat objek dan merasakan pengalaman dari suatu objek. Pada usia ini, pemberian pengetahuan di sekolah mampu memberikan kesempatan pada mereka untuk mempelajari konsep, melakukan interferensi, mendapatkan pengetahuan dan menyebarkan pengetahuan ke lingkungan sekitarnya (Gardner, 2011).

Program Sanitarian Cilik ini diselenggarakan di Sekolah Dasar Negeri 011 yang terletak di Jl. Danau Maninjau No. 4 Kelurahan Sungai Pinang Luar, Kota Samarinda. Pemilihan lokasi sekolah ini didasarkan atas kriteria khusus yaitu sekolah ini terletak di wilayah sekitaran Sungai Karang Mumus. Berdasarkan hasil observasi yang dilakukan diperoleh hasil bahwa sanitasi masyarakat yang tinggal dipinggiran Sungai Karang Mumus masih belum dikelola dengan baik. Kondisi air Sungai Karang Mumus kotor dan tercemar akibat dari aktivitas masyarakat yang membuang sampah di sungai. Selain itu, masyarakat sekitar sungai Karang Mumus juga memanfaatkan air Sungai Karang Mumus untuk MCK (mandi, cuci dan kakus). Oleh karena itu, perlu dilakukan pembekalan 
pengetahuan mengenai pola perilaku hidup bersih dan sehat kepada masyarakat melalui kader-kader Sanitarian Cilik.

\section{METODE PELAKSANAAN}

Program Sanitarian Cilik ini diselenggarakan pada hari Kamis, 12 April 2018 di Sekolah Dasar (SD) Negeri 011 yang terletak di Jl. Danau Maninjau No. 4 kelurahan Sungai Pinang Luar, Kota Samarinda. Pemilihan lokasi sekolah ini didasarkan atas kriteria khusus yaitu sekolah ini terletak di wilayah sekitaran sungai Karang Mumus.

Metode yang digunakan dalam kegiatan program sanitarian cilik ini adalah metode Ceramah, tanya jawab dan praktik. Bentuk kegiatan yang dilaksanakan dalam Program Sanitarian Cilik adalah sebagai berikut:

\section{1) Pretest PHBS}

Kegiatan pertama yang dilakukan dalam kegiatan ini yaitu melakukan pretest mengenai PHBS. Soal dalam pretest ini terdiri dari 10 soal. Hal ini dilakukan untuk menilai sejauh mana pemahaman siswa mengenai PHBS. Penilaian pretest pemahaman siswa mengenai PHBS dikategorikan menjadi 2 kategori, yaitu:

Baik = Jika nilai pemahaman PHBS siswa $\geq 8$

Tidak Baik = Jika nilai pemahaman PHBS siswa $<8$

2) Pemberian materi mengenai Perilaku Hidup Bersih dan Sehat (PHBS)

Pemberian materi PHBS dilakukan melalui metode ceramah disertai dengan ditayangkannya slide power point dan video, tanya jawab dan praktik mengenai materi yang disampaikan. Pada materi ini disampaikan bagaimana seharusnya menjaga kesehatan dengan cara ber-PHBS.

3) Praktik Mencuci tangan dengan air mengalir yang bersih dan menggunakan sabun

Praktik Mencuci tangan dilakukan untuk memberikan pemahaman kepada siswa cara mencuci tangan yang baik dan benar.

4) Praktik menggosok gigi yang baik dan benar

Praktik sikat gigi dilakukan untuk memberikan pemahaman kepada siswa cara menyikat gigi yang benar

5) Praktik memilah sampah yang benar

Praktik memilah sampah dilakukan agar siswa dapat mengetahui jenis sampah, sehingga dapat memilah dan membuang sampah pada tempatnya.

6) Posttest PHBS

Posttest PHBS dilakukan untuk menilai perubahan pemahaman siswa setelah diberikan materi PHBS. Soal dalam pretest ini terdiri dari 10 soal. Penilaian posttest pemahaman siswa mengenai PHBS dikategorikan menjadi 2, yaitu:

Baik = Jika nilai pemahaman PHBS siswa $\geq 8$

Tidak Baik $=$ Jika nilai pemahaman PHBS siswa $<8$

Data hasil pretest dan posttest diolah menggunakan SPSS. Untuk menguji adanya perbedaan pemahaman PHBS siswa sebelum dan sesudah dilakukan edukasi dilakukan uji beda ( uji- $t$ berpasangan atau uji wilcoxon ) untuk skala rasio. Untuk menentukan uji 
beda yang akan digunakan terlebih dahulu dilakukan uji normalitas data menggunakan uji Kolmogorov-Smirnov karena jumlah sampel lebih dari 40. Apabila uji KolmogorovSmirnov didapatkan data berdistribusi normal, maka uji beda yang digunakan adalah uji$t$ berpasangan sedangkan jika uji Kolmogorov-Smirnov didapatkan data berdistribusi tidak normal, maka uji beda yang digunakan adalah uji Wilcoxon.

7) Pemilihan Kader Sanitarian Cilik

Pemilihan Kader sanitarian cilik bagi peserta yang memiliki kemampuan baik dalam menyerap materi.

8) Pemberian penghargaan bagi kader Sanitarian Cilik yang terpilih.

\section{HASIL DAN PEMBAHASAN}

Kegiatan pengabdian kepada masyarakat ini dilaksanakan di Sekolah Dasar (SD) Negeri 011 yang terletak di Jl. Danau Maninjau No. 4 kelurahan Sungai Pinang Luar, Kota Samarinda yang diikuti oleh siswa kelas 3 dan 4 . Siswa yang mengikuti acara ini terdaftar sejumlah 90 siswa. Tahap kegiatan pengabdian kepada masyarakat ini adalah:

\section{Pelaksanaan Pretest}

Kegiatan pertama dalam acara ini adalah melakukan pretest mengenai PHBS yang merupakan singkatan dari Perilaku Hidup Bersih dan Sehat. Hal ini dilakukan untuk menilai sejauh mana pemahaman siswa mengenai PHBS. Hasil pretest dapat dilihat pada tabel berikut:

Tabel 1. Hasil pretest Pemahaman PHBS Siswa Kelas 3 dan 4 SDN 011 Kota Samarinda, Tahun 2018

\begin{tabular}{lll}
\hline Pemahaman PHBS & $\mathrm{n}$ & $\%$ \\
\hline Baik & 79 & 87,8 \\
Tidak Baik & 11 & 12,2 \\
Total & 90 & 100 \\
\hline
\end{tabular}

Tabel 1. Hasil pretest Pemahaman PHBS kelas 3 dan 4 menunjukkan bahwa terdapat $79(87,8 \%)$ siswa yang mempunyai pemahaman baik dan $11(12,2 \%)$ siswa yang mempunyai pemahaman tidak baik.

\section{Pemberian Materi dan Praktik PHBS}

Pemberian materi PHBS dilakukan melalui metode ceramah disertai dengan ditayangkannya slide power point, video dan tanya jawab mengenai materi yang disampaikan. Pada materi ini disampaikan bagaimana seharusnya menjaga kesehatan dengan cara ber-PHBS. Selain itu, dilakukan juga praktik mencuci tangan di air mengalir dengan menggunakan sabun, menggosok gigi yang benar, dan memilah sampah. Tujuan kegiatan praktik langsung ini adalah agar siswa dapat lebih mudah memahami materi serta bisa menerapkannya dalam kehidupan sehari-hari dengan baik dan benar.

Perilaku Hidup Bersih dan Sehat (PHBS) adalah sekumpulan perilaku yang dipraktekkan atas dasar kesadaran sebagai hasil pembelajaran, yang menjadikan seseorang, keluarga, kelompok atau masyarakat mampu menolong dirinya sendiri (mandiri) di bidang kesehatan dan berperan aktif dalam mewujudkan kesehatan 
masyarakat. Dengan demikian, PHBS mencakup banyak perilaku yang harus dipraktekkan dalam rangka mencapai derajat kesehatan masyarakat yang setinggitingginya. PHBS yang harus dipraktekkan dalam kehidupan sehari-hari yaitu Mencuci tangan dengan air yang mengalir dan menggunakan sabun, Menggosok gigi, Mengkonsumsi jajan sehat, Menggunakan jamban yang bersih dan sehat, Membuang sampah pada tempatnya, Olahraga yang teratur, Memberantas jentik nyamuk secara teratur, dan Tidak merokok.

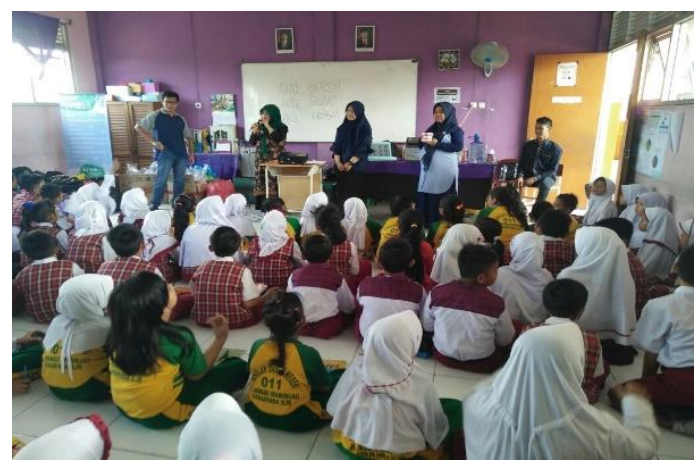

Gambar 1. Pemberian Materi PHBS untuk mengenalkan dan meningkatkan pemahaman siswa terkait pentingnya ber-PHBS dalam kehidupan sehari-hari

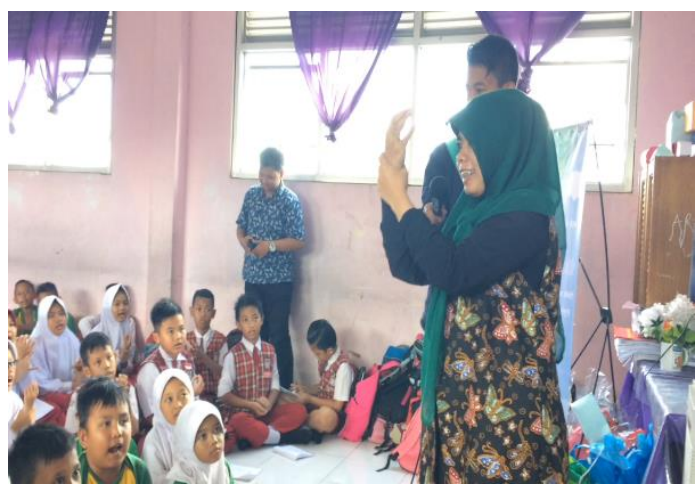

Gambar 2. Praktik Mencuci tangan untuk memberikan pemahaman kepada siswa cara mencuci tangan yang benar

\section{Pelaksanaan Posttest}

Setelah pemberian materi dan praktik PHBS, selanjutnya dilakukan posttest. Soal dalam pretest ini terdiri dari 10 soal. Hal ini dilakukan untuk menilai apakah ada perbedaan pemahaman siswa mengenai PHBS setelah diberikan materi dan praktik PHBS. Hasil posttest dapat dilihat pada tabel berikut:

Tabel 2. Hasil posttest Pemahaman PHBS Siswa Kelas 3 dan 4 SDN 011 Kota Samarinda,

Tahun 2018

\begin{tabular}{lll}
\hline Pemahaman PHBS & $\mathrm{n}$ & $\%$ \\
\hline Baik & 89 & 98,9 \\
Tidak Baik & 1 & 1,1 \\
Total & 90 & 100 \\
\hline
\end{tabular}


Tabel 2 Hasil posttest Pemahaman PHBS kelas 3 dan 4 menunjukkan bahwa terdapat $89(98,9 \%)$ siswa yang mempunyai pemahaman baik dan $1(1,1 \%)$ siswa yang mempunyai pemahaman tidak baik. Selanjutnya, untuk melihat adanya perbedaan pemahaman PHBS sebelum dan sesudah dilakukan kegiatan edukasi , dilakukan uji Wilcoxon. Uji Wilcoxon dilakukan karena data tidak memenuhi kaidah normalitas data ( $\mathrm{p}$-value $<0,05$ ).

Tabel 3. Hasil uji normalitas data pretest dan posttest (uji Kolmogorov-Smirnov)

\begin{tabular}{lll}
\hline Normalitas & Pretest & Posttest \\
\hline Kolmogorov-Smirnov Z & 3,741 & 4,908 \\
Asymp. Sig. (2-tailed) & 0,000 & 0,000 \\
\hline
\end{tabular}

Setelah dilakukan uji normalitas dengan menggunakan uji statistik KolmogorovSmirnov, didapatkan hasil bahwa memenuhi kaidah normalitas data ( $p$-value $>0,05$ ). Sehingga uji statistik yang akan digunakan untuk melihat perbedaan pemahaman PHBS sebelum dan sesudah dilakukan Edukasi pada Siswa Kelas 3 dan 4 SDN 011 Kota Samarinda (Independent Sample T-Test).

Tabel 4. Pemahaman PHBS Sebelum dan Sesudah Kegiatan Edukasi pada Siswa Kelas 3 dan 4 SDN 011 Kota Samarinda, Tahun 2018

\begin{tabular}{ll}
\hline & Posttest - Pretest \\
$\mathrm{Z}$ & $-3,574 \mathrm{~b}$ \\
Asymp. Sig. (2-tailed) & 0,000 \\
\hline
\end{tabular}

Tabel 4. Menunjukkan bahwa edukasi PHBS yang dilakukan pada siswa kelas 3 dan 4 Sekolah Dasar Negeri 011 Kota Samarinda diperoleh nilai Z sebesar -3,574 dengan $\mathrm{p}$ value (Asymp. Sig 2 tailed) sebesar 0,000. Hal ini dapat disimpulkan bahwa terdapat perbedaan bermakna pemahaman PHBS sebelum dan sesudah dilakukan kegiatan edukasi PHBS.

\section{Pemilihan Kader Sanitarian Cilik}

Pemilihan kader sanitarian cilik didasarkan atas kriteria pemahaman siswa terhadap materi yang telah disampaikan sebelumnya. Penilaian pemahaman materi peserta didasarkan pada keaktifan dan hasil posttest. Pada kegiatan ini terpilih 6 orang sanitarian cilik yaitu 1 orang kelas 3 dan 5 orang kelas 4 . Sebagai keberlanjutan pelaksanaan program ini adalah diadakannya pembinaan terhadap kader sanitarian cilik dengan materi mengenai PHBS yang lebih luas lagi. Kader sanitarian cilik ini diharapkan mampu menerapkan dan menyebarluaskan informasi terkait pola perilaku hidup bersih dan sehat kepada keluarga dan lingkungannya dalam mewujudkan kesehatan masyarakat yang lebih baik.

Pengarahan kepada kader sanitarian cilik agar dapat menerapkan dan menyebarluaskan informasi terkait PHBS kepada teman, keluarga dan lingkungan sehingga tercipta masyarakat yang sehat. Program Perilaku Hidup Bersih dan Sehat (PHBS) merupakan upaya untuk memberikan pengalaman belajar atau menciptakan suatu kondisi bagi perorangan, keluarga, kelompok dan masyarakat, dengan membuka jalur komunikasi, memberikan informasi dan melakukan edukasi, untuk meningkatkan pengetahuan, sikap dan perilaku, melalui pendekatan pimpinan (Advokasi), bina suasana 
(Social Support) dan pemberdayaan masyarakat (Empowerment). Dengan demikian masyarakat mampu mengenali dan mengatasi masalahnya sendiri, terutama dalam tatanan masing-masing, serta mampu menjaga dan memelihara serta meningkatkan kesehatannya dengan menerapkan cara-cara hidup sehat (Permenkes RI, 2011).

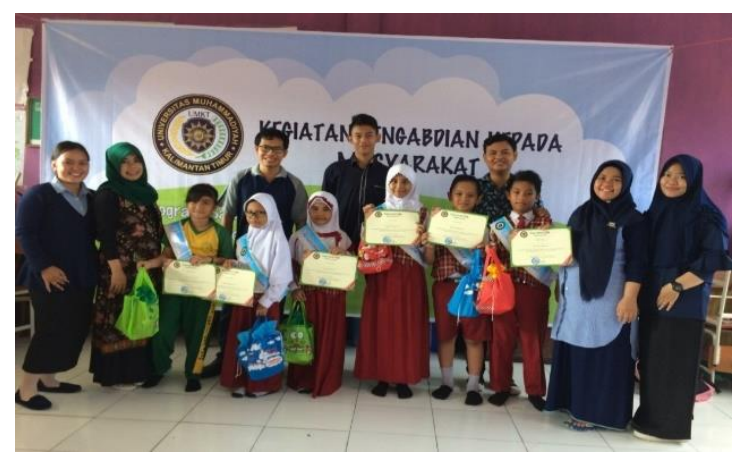

Gambar 3. Foto Bersama Kader Sanitarian Cilik Terpilih Sebagai Agent of Change

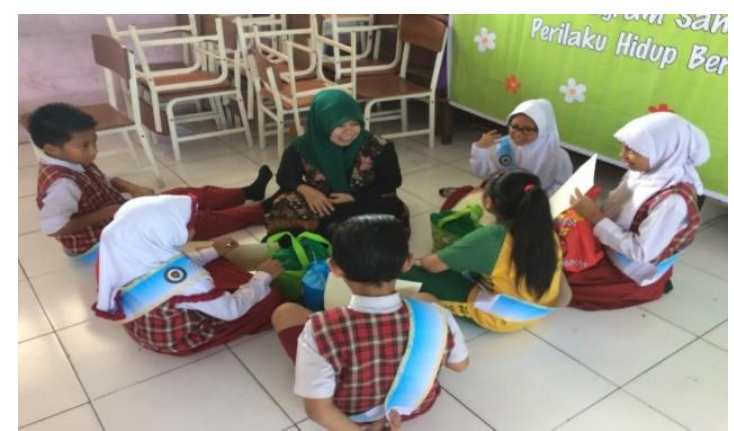

Gambar 4. Pengarahan Kepada Kader Sanitarian Cilik

Program Sanitarian Cilik ini diharapkan dapat berjalan dan memberikan hasil atau dampak yang signifikan terhadap peningkatan kesehatan masyarakat. Demi tercapainya hal tersebut, maka perlu dilakukan pemantauan dan evaluasi. Tolak ukur keberhasilan program sanitarian cilik ini adalah kader sanitarian cilik mampu menerapkan dan menyebarluaskan informasi terkait Pola Perilaku Hidup Bersih dan Sehat kepada teman, keluarga dan lingkungan sehingga tercipta masyarakat yang sehat.

\section{SIMPULAN}

Edukasi pola Perilaku Hidup Bersih dan Sehat kepada masyarakat melalui program Sanitarian Cilik di Sekolah Dasar telah berhasil dilaksanakan. Dari kegiatan ini dapat disimpulkan bahwa terdapat perbedaan bermakna pemahaman PHBS sebelum dan sesudah dilakukan kegiatan edukasi. Dari kegiatan ini juga telah dihasilkan 6 kader sanitarian cilik yaitu 1 orang kelas 3 dan 5 orang kelas 4 . Kader sanitarian ini diharapkan mampu menerapkan dan menyebarluaskan informasi terkait PHBS kepada keluarga dan lingkungannya. Selanjutnya, untuk keberlanjutan program ini maka perlu adanya pembinaan dan kerjasama dengan Dinas Kesehatan dan Dinas Pendidikan Pemuda dan Olahraga setempat untuk Program Sanitarian Cilik. 


\section{UCAPAN TERIMA KASIH}

Penulis mengucapkan terima kasih kepada Universitas Muhammadiyah Kalimantan Timur yang telah mendanai pelaksanaan pengabdian kepada masyarakat ini serta kepada semua pihak yang terlibat baik secara teknis maupun non teknis.

\section{REFERENSI}

Andriansyah, Y., \& Rahmantari, D. N. (2013). Penyuluhan dan praktik PHBS (perilaku hidup bersih sehat) dalam mewujudkan masyarakat desa peduli sehat. Jurnal Inovasi dan Kewirausahaan, 2(1), 45-50.

Dahlan, S. (2009). Statistik untuk kedokteran dan kesehatan (Edisi 4). Jakarta: Salemba Medika.

Depkes RI. (2007). Keputusan Menteri Kesehatan nomor 373 Tahun 2007 tentang Standart Profesi Sanitarian. Retrieved December 15, 2017, from http://perpustakaan.depkes.go.id:8180/bitstream/123456789/1235/3/KMK373-0307G.pdf.

Depkes RI. (2011). Peraturan Menteri Kesehatan Republik Indonesia Nomor. 22692011 tentang Pedoman Perilaku Hidup Bersih dan Sehat. Retrieved January 02, 2018, from http://promkes.depkes.go.id/wpcontent/uploads/pdf/buku_pedoman/pedoman_u mum_PHBS.pdf.

Depkes RI. (2015). Profil kesehatan provinsi Kalimantan Timur. Retrieved December 30, 2017, from

http://www.depkes.go.id/resources/download/profil/PROFIL_KES_PROVINSI_201 5/23_KALTIM_2015.pdf.

Gardner, H. (2011). Frames of mind: The theory of multiple intelligences (3rd edition). New York: Basic Book.

Linda, O., \& Adiwiryono, R. M. (2010). Praktik perilaku hidup bersih dan sehat (PHBS) pada peserta pendidikan anak usia dini (PAUD) di Kecamatan Koja, Jakarta Utara Tahun 2010. Jakarta: Universitas Muhamadiyah Prof. Dr. Hamka.

Notoatmodjo, S.(2003). Prinsip-Prinsip Dasar Ilmu Kesehatan Masyarakat. Cet. ke-2. Jakarta: Rineka Cipta.

Undang-undang Nomor 23 tahun 1992. Retrieved December 12, 2018, from http://www.balitbangham.go.id/pocontent/peraturan/uu.\%20no\%2023\%20tahun\%2 01992\%20tentang\%20kesehatan.pdf. 